\title{
Development of Ti-Bi-based nanomaterials to purify mercury in the simulated flue gas
}

\author{
$Y u$ Guan $^{1}$, Lingjie $\mathrm{Yu}^{2}$, Jiang $\mathrm{Wu}^{1, *}$, Xiaoming Sun ${ }^{1}$ \\ ${ }^{1}$ College of Energy and Mechanical Engineering, Shanghai University of Electric Power, Shanghai 200090, China \\ ${ }^{2}$ Shanghai Waigaoqiao Power Generation Co., Ltd., Shanghai 200137, China
}

\begin{abstract}
The photocatalytic oxidation technology is a new technology for the oxidation treatment of $\mathrm{Hg}^{0}$ developed in the existing Wet Flue Gas Desulfurization (WFGD) equipment, in which the removal efficiency of $\mathrm{Hg}^{2+}$ is high and the removal efficiency of $\mathrm{Hg}^{0}$ is very low. When ultraviolet light (UV) is used to irradiate a substance containing $\mathrm{TiO}_{2}$ to pass the flue gas, photocatalytic catalytic oxidation reaction occurs, and $\mathrm{Hg}^{0}$ is oxidized to $\mathrm{Hg}^{2+}$, which is easily absorbed later in the WFGD apparatus, thereby improving the removal efficiency of mercury. The technology is still in the experimental development stage and needs further research. It has brought widespread interests to introduce surface defect or form interface heterostructure to improve the photocatalytic activity of the nanomaterials. The Ti-Bi-based nanomaterial photocatalyst with defect $\mathrm{TiO}_{2} / \mathrm{BiOIO}_{3}$ heterostructure has been fabricated via calcination method. The results showed that to introduce surface defect and form interface heterostructure on photocatalysts together can increase the response of the visible light, promoting the transfer velocity of the photocarriers and in turn suppressing the recombination of photo-generated electrons and holes, and this may become a developing trend in the near future.
\end{abstract}

\section{Introduction}

China is a large coal country that the main source of energy is coal, and many pollutants emitted during the coal combustion process, because mercury is a highly toxic trace element in coal and is discharged into the atmosphere with the combustion process of coal. It has the physicochemical properties of low melting point, low boiling point, high volatility and so on.

There exist three forms of mercury in the coal-fired power plant: elemental mercury $\left(\mathrm{Hg}^{0}\right)$, oxidized mercury $\left(\mathrm{Hg}^{2+}\right)$, and particulate-bound mercury $\left(\mathrm{Hg}^{\mathrm{p}}\right)^{[1]}$. The removal of mercury in the flue gas is largely dependent on the form of mercury. The oxidized mercury $\left(\mathrm{Hg}^{2+}\right)$ is easily soluble in water, so the oxidized mercury can be removed by the wet electrostatic precipitator, and the efficiency can reach $90 \%$. Particulate-bound mercury can easily pass through the dedusting devices in the power plant. But the elemental mercury is volatility, insoluble in water and chemical stability, it's not easily removed by the existing power plant air pollutant removal equipment. Thus, the elemental mercury removal in coal-fired power plants is a huge challenge, the key difficulty being converting $\mathrm{Hg}^{0}$ into $\mathrm{Hg}^{2+}$.

It has great harm to the environment and human body. Removing mercury from flue gas, photocatalytic oxidation technology has the advantages of strong oxidation capacity, no twice pollution and stable chemical properties. Thus, it has broad application prospects in the treatment of flue gas mercury removal.

In this paper, we conducted the physicochemical property of Ti-Bi-based nanomaterials by XRD, SEM and XPS. The performance of the catalyst was evaluated by visible light photocatalytic removal of gas mercury. In addition, the mechanism of the removal of zero valent mercury by photocatalytic oxidation is also clarified. After modification, the visible light absorption is enhanced, the photoelectron hole separation efficiency is increased, and its recombination is inhibited. The surface performance parameters are improved. All these factors are favorable for the photocatalytic removal of mercury efficiency.

\section{Experimental}

\subsection{Chemicals and materials}

Bismuth nitrate pentahydrate, commercial P25 $\left(\mathrm{TiO}_{2}\right)$ and potassium iodate were all obtained from Shanghai Aladdin Reagent Co., Ltd. All solutions were prepared with deionized water and all chemicals used were analytical grade and were used without further purification.

\footnotetext{
* Corresponding author: wjcfd2002@163.com
} 


\subsection{Preparation of defect $\mathrm{TiO}_{2}$}

The synthesis of defect $\mathrm{TiO}_{2}$ was described, which was similar to that used in our previous study ${ }^{[2]}$. In a typical process, $\mathrm{TiO}_{2}$ powder was dissolve in $50 \mathrm{ml}$ Ethyl stirring for $1 \mathrm{~h}$, and then, the powder was dried at $80^{\circ} \mathrm{C}$ for $12 \mathrm{~h}$. Finally, the defect $\mathrm{TiO}_{2}$ was obtained.

\subsection{Preparation of defect $\mathrm{BiOlO}_{3}$}

In a typical process, 1 mmol bismuth nitrate pentahydrate was added to $70 \mathrm{ml}$ deionized water and stirring $30 \mathrm{~min}$, then $1 \mathrm{mmol}$ potassium iodate was dissolved in the above suspension. After stirring for $1 \mathrm{~h}$ in dark, the product was acquired by filtering and obtained after being washed with deionized water and ethanol for three times respectively, and then dried at $80^{\circ} \mathrm{C}$ for $12 \mathrm{~h}$. The obtained product was ground into powders, then calcined in the muffle furnace for $1 \mathrm{~h}$ under $200{ }^{\circ} \mathrm{C}$.

\subsection{Preparation of defect $\mathrm{TiO}_{2} / \mathrm{BiOIO}$ nanomaterials.}

Defect $\mathrm{TiO}_{2}$ and defect $\mathrm{BiOIO}_{3}$ was transferred into 80 $\mathrm{ml}$ deionized water and stirred for $10 \mathrm{~min}$, then transferred into $100 \mathrm{ml}$ Teflon under $150^{\circ} \mathrm{C}$ for $8 \mathrm{~h}$. The product washing thoroughly with deionized water and ethanol three times respectively, the obtained sample was dried in an oven at $80^{\circ} \mathrm{C}$ for $12 \mathrm{~h}$. The mole ratios of $\mathrm{TiO}_{2}: \mathrm{BiOIO}_{3}$ at 1:0.1 and 1:0.2 were labeled as $\mathrm{TiO}_{2}-0.1$ and $\mathrm{TiO}_{2}-0.2$.

\subsection{Materials Characterization}

Powder X-ray diffraction (XRD) with $\mathrm{Cu} \mathrm{K} \alpha$ radiation (BRUKER D8 ADVANCE Diffractometer, Germany) was applied to exam the crystalline phase of as-prepared samples. Scanning electron microscope (SEM, Phillips XL-30 FEG/NEW) was used to investigate the morphology of the samples. X-ray photoelectron spectroscopy (XPS, PHI5300) was utilized to investigate the surface chemical composition and chemical states of the samples.

\subsection{Measurement of photoactivity}

The photocatalytic experimental system is developed by ourselves ${ }^{[3]}$. The experimental system consists of a simulated flue gas mercury system, a mercury generating device, a photocatalytic reaction system, a flue gas mercury testing system, and an exhaust gas system. They are all connected by Teflon tube. A certain concentration of elemental mercury $\left(\mathrm{Hg}^{0}\right)$ is produced at a certain temperature and carried into the photocatalytic system by simulated flue gas or pure nitrogen. The high-purity nitrogen gas is divided into two paths, which are controlled by the mass flow controller. One gas is used as a carrier gas through the U-shaped glass tube, and the zero-valent mercury volatilized from the mercury permeation tube is carried out, and the other gas is evenly distributed in the gas mixing tank. mixing. Nitrogen carrying mercury vapor was tested online for mercury removal by a mercury analyzer (RA-915M, Lumex, Russia). Finally, the gas was introduced into the potassium permanganate solution to absorb residual mercury and then emptied.

\section{Results and discussions}

\subsection{Structure, Composition, and Morphology}

XRD of defect $\mathrm{TiO}_{2}$, defect $\mathrm{BiOIO}_{3}$, and defect $\mathrm{TiO}_{2} / \mathrm{BiOIO}_{3}$ heterostructures are shown in Fig. 1. For defect $\mathrm{TiO}_{2}$, the seven diffraction peaks at $2 \theta=25.16^{\circ}$, $27.25^{\circ}, 37.65^{\circ}, 47.89^{\circ}, 53.82^{\circ}, 55.02^{\circ}, 62.62^{\circ}$ agree well with commercial P25. For defect $\mathrm{BiOIO}_{3}$, the characteristic diffraction peaks at $27.28^{\circ}, 32.79^{\circ}, 44.87^{\circ}$, $45.53^{\circ}$, and $53.65^{\circ}$ are observed and these peaks could be perfectly indexed to (121), (002), (040), (212), and (123) planes of orthorhombic $\mathrm{BiOIO}_{3}(\mathrm{ICSD}$ \# 262019). For defect $\mathrm{TiO}_{2} / \mathrm{BiOIO}_{3}$ heterostructures, $\mathrm{TiO}_{2}-0.1$ and $\mathrm{TiO}_{2}-0.2$, all the peaks can be match with $\mathrm{TiO}_{2}$ or $\mathrm{BiOIO}_{3}$. Thus, it was successfully fabricated.

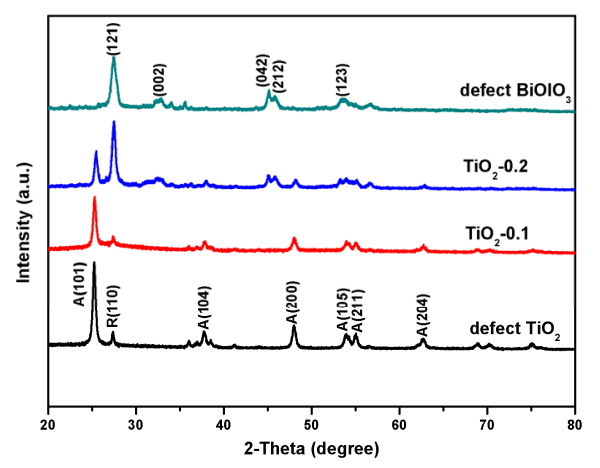

Fig. 1. Typical XRD patterns of defect $\mathrm{TiO}_{2}$, defect $\mathrm{TiO}_{2} / \mathrm{BiOIO}{ }_{3}$ heterostructures, and defect $\mathrm{BiOIO}_{3}{ }^{[11]}$.

As shown in Figure 2, FESEM characterization is used to observe the morphology of the as-prepared samples. The defect $\mathrm{TiO}_{2}$ possesses a diameter of ca. 25 $\mathrm{nm}$, which is the mix phase of anatase and rutile, as confirmed by the above XRD analysis. The defect $\mathrm{BiOIO}_{3}$ (Fig. 2d) exhibits irregular shapes because of fabrication by calcination method. For $\mathrm{TiO}_{2}-0.1$ and $\mathrm{TiO}_{2}-0.2$ (Fig. $2 \mathrm{~b}$ and c), the defect $\mathrm{BiOIO}_{3}$ is distributed in the defect $\mathrm{TiO}_{2}$ with an intimate interfacial contact. The tight heterostructure formed by $\mathrm{TiO}_{2}$ attaching to $\mathrm{BiOIO}_{3}$ forming the tight heterostructure can enhance the photocarriers' transferring velocity between the $\mathrm{TiO}_{2}$ and $\mathrm{BiOIO}_{3}$. For defect $\mathrm{BiOIO}_{3}$ shown in figure 2d, all the $\mathrm{BiOIO}_{3}$ exhibits irregular shapes.

The surface composition and chemical status of the asprepared defect $\mathrm{TiO}_{2}, \mathrm{TiO}_{2}-0.1, \mathrm{TiO}_{2}-0.2$ and defect $\mathrm{BiOIO}_{3}{ }^{[4]}$ are investigated by XPS characterization. The high resolution XPS spectra of $\mathrm{TiO}_{2}-0.1$ and $\mathrm{TiO}_{2}-0.2$ are demonstrated in the Fig. 3, the peaks at 458.23 and $464.26 \mathrm{eV}$ can be attributed $\mathrm{Ti} 2 \mathrm{p} 3 / 2$ and $\mathrm{Ti} 2 \mathrm{p} 1 / 2$, consistent with other researchers reports ${ }^{[5,6]}$. The O 1 s 
spectra of $\mathrm{TiO}_{2}-0.1$ shown in Fig. 3b. The peaks at $528.98,530.17,531.28$, and $532.26 \mathrm{eV}$ can be defined as $\mathrm{Bi}-\mathrm{O}^{[7,8]}, \mathrm{Ti}-\mathrm{O}^{[9]}, \mathrm{I}-\mathrm{O}^{[10]}$, and surface absorbed oxygen ($\mathrm{OH}$ group and chemisorbed oxygen-containing species) respectively.
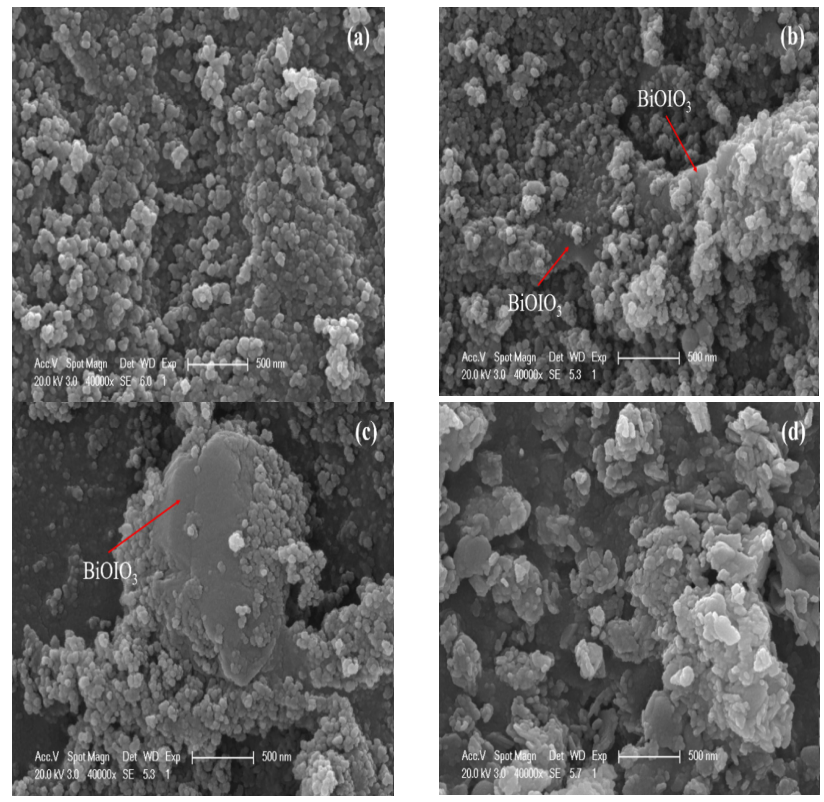

Fig. 2. FESEM images of defect $\mathrm{TiO}_{2}(\mathrm{a}), \mathrm{TiO}_{2}-0.1(\mathrm{~b}) ; \mathrm{TiO}_{2}-$ $0.2(\mathrm{c})$, and defect $\mathrm{BiOIO}_{3}(\mathrm{~d})^{[11]}$.
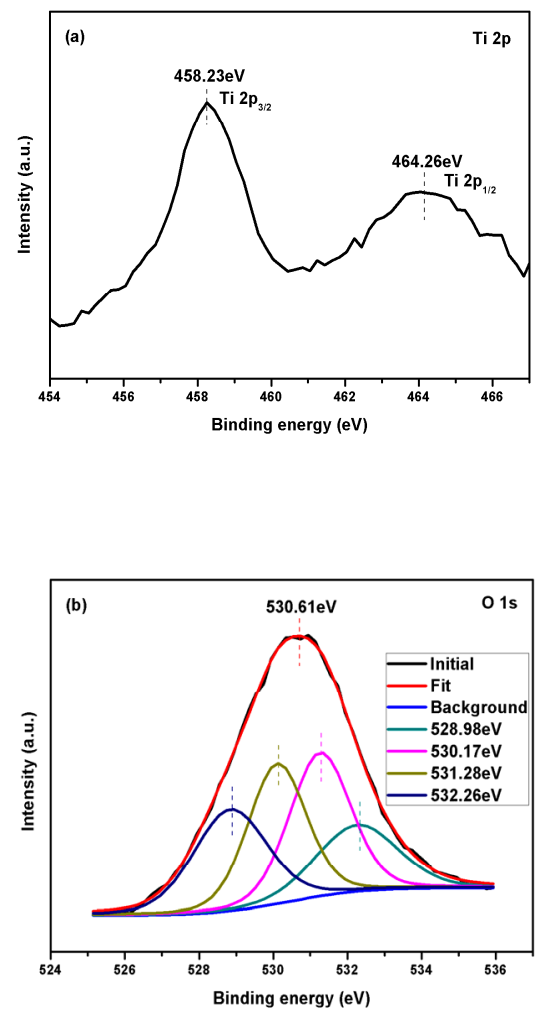

Fig. 3. XPS spectra of TiO2-0.1: (a) Ti 2p, (b) O 1s (All the peak maxima were calibrated to $\mathrm{C} 1 \mathrm{~s}$ at $284.6 \mathrm{eV}$, which was mainly ascribed to remnant organic precursors not completely removed from the employed defect $\mathrm{TiO}_{2} / \mathrm{BiOIO}_{3}$ heterostructure ${ }^{[11]}$.

\subsection{Photocatalytic activity properties}

\subsection{1 $\mathrm{Hg}^{0}$ removal under LED irradiation}

At present, there are two main sources of light sources for existing photocatalytic reactors: natural light sources and artificial light sources. Among them, the natural light source is sunlight; the artificial light source is generally divided into a visible light source and an ultraviolet light source. All the light sources in this experiment are artificial light sources. The ultraviolet light source uses an ultraviolet lamp with a power of $400 \mathrm{~W}$. The ultraviolet light has a peak wavelength of $365 \mathrm{~nm}$ and the overall length of the lamp is $150 \mathrm{~mm}$. It is equipped with UV lamps around it. Reflective device. The visible light source uses a white LED light source with a power of $9 \mathrm{~W}$. The simulated solar light source uses an LED light source with a $410 \mathrm{~nm}$ filter, which filters the light source with a wavelength of less than 410 $\mathrm{nm}$.

The defect $\mathrm{TiO}_{2}$, defect $\mathrm{BiOIO}_{3}$, and defect $\mathrm{TiO}_{2} / \mathrm{BiOIO}_{3}$ heterostructure photocatalysts were adopted to remove the gas-phase $\mathrm{Hg}^{0}$ for investigating the photocatalytic performance of the as-prepared photocatalysts. As shown in Table 1, the photocatalytic efficiency of defect $\mathrm{TiO}_{2}$ was $28.56 \%$ and the photocatalytic efficiency of defect $\mathrm{BiOIO}_{3}$ was $58.23 \%$ under LED irradiation.

Table 1. Photocatalytic removal gas-phase $\mathrm{Hg}^{0}$ under 9 W LED lamp irradiation for $1 \mathrm{~h}$ by defect $\mathrm{TiO}_{2}$, defect $\mathrm{TiO}_{2} / \mathrm{BiOIO}_{3}$ heterostructures, and defect $\mathrm{BiOIO}_{3}$.

\begin{tabular}{|l|l|l|l|l|}
\hline Samples & $\begin{array}{l}\text { Defect } \\
\mathrm{TiO}_{2}\end{array}$ & $\begin{array}{l}\text { Defect } \\
\mathrm{BiOIO}_{3}\end{array}$ & $\begin{array}{l}\mathrm{TiO}_{2-} \\
0.1\end{array}$ & $\begin{array}{l}\mathrm{TiO}_{2-} \\
0.2\end{array}$ \\
\hline Efficiency & $28.56 \%$ & $58.23 \%$ & $89.15 \%$ & $72.35 \%$ \\
\hline
\end{tabular}

\subsubsection{The stability of the photocatalysts}

The stability of photocatalysts is vitally important for its application. In this paper, we used $\mathrm{TiO}_{2}-0.1$ as a representative sample to investigate the stability of asprepared photocatalysts. The stability of $\mathrm{TiO}_{2}-0.1$ is not changed after seven cycles tests, which confirms that $\mathrm{TiO}_{2}-0.1$ possesses high stability.

\subsection{Photocatalytic reaction mechanisms}

\subsubsection{Introducing surface defect}

For pure $\mathrm{TiO}_{2}$ and $\mathrm{BiOIO}_{3}$, the band gap is 3.15 and $3.13 \mathrm{eV}$, respectively. According to the equation: $\lambda_{\text {absorbance edge }}=1240 / \mathrm{E}_{\mathrm{bg}}$, thus the absorbance edge of pure $\mathrm{TiO}_{2}$ and $\mathrm{BiOIO}_{3}$ is 393.65 and $396.16 \mathrm{~nm}$ respectively. The broad band gap and low absorbency severely restrict the pure $\mathrm{TiO}_{2}$ and $\mathrm{BiOIO}_{3}$ visible light photocatalytic activity. Furthermore, the charge separation efficiency between conduction band and valence band is weak, which is another reason for low photocatalytic activity. Introducing surface defect may distort the crystal lattice on the surface of $\mathrm{TiO}_{2}$ and $\mathrm{BiOIO}_{3}$, which would 
produce a lot of mid-gap states. Because the lowerenergy mid-gap lies below the Fermi level, they can account for a large blue shift of the valence band edge result in a reduced band gap. For defect $\mathrm{TiO}_{2}$ and $\mathrm{BiOIO}_{3}$, the band gap is 2.66 and $2.96 \mathrm{eV}$, respectively and the absorbance edge of defect $\mathrm{TiO}_{2}$ and $\mathrm{BiOIO}_{3}$ is 466 and $418 \mathrm{~nm}$, respectively. Despite all this, the photocatalytic activity of defect $\mathrm{TiO}_{2}$ and defect $\mathrm{BiOIO}_{3}$ is low due to the rapid combination of photo generated electron-hole pairs ${ }^{[11]}$.

\subsubsection{Effect of interface heterostructure}

The crystal lattice defects on the surface of $\mathrm{TiO}_{2}$ and $\mathrm{BiOIO}_{3}$ produce mid-gap states. The mid-gap between the conduction band and valence band can narrow the band gap and absorb more visible light. When the light irradiates on the surface of defect $\mathrm{TiO}_{2}$ or defect $\mathrm{BiOIO}_{3}$, the photo-generated electrons transfer from the valence band to conduction band, forming photo separation electron-hole pairs. Due to the rapid recombination of electron-hole pairs and the low transfer velocity between the conduction band and valence band, the photocatalytic removal $\mathrm{Hg}^{0}$ efficiency of defect $\mathrm{TiO}_{2}$ or defect $\mathrm{BiOIO}_{3}$ is poor. Under the LED irradiation, the photocatalysts can absorb the low light response range, slow transfer velocity of photocarriers and rapid recombination of the electron-hole pairs. However, under the UV irradiation, the photocatalysts can extend the light absorbance to the visible even infrared light region. Therefore, under the UV irradiation, the photocatalysts have higher catalytic efficiency than LED irradiation. However, when attaching the defect $\mathrm{BiOIO}_{3}$ to the surface of defect $\mathrm{TiO}_{2}$ to form the interface heterostructures, the photogenerated electrons can transfer from conduction of $\mathrm{TiO}_{2}$ to the conduction of $\mathrm{BiOIO}_{3}$. Meanwhile, the photogenerated holes can transfer from the valence of $\mathrm{BiOIO}_{3}$ to the valence of $\mathrm{TiO}_{2}$. Thus, the transformation of photo-generated electron-hole pairs between defect $\mathrm{TiO}_{2}$ and $\mathrm{BiOIO}_{3}$ can effectively inhibit the recombination of photo-generated electron-hole pairs and efficiently enhance the transfer velocity of photo carriers. The generated $\mathrm{O}_{2}^{-}$and $\mathrm{OH}$ by defect $\mathrm{TiO}_{2} / \mathrm{BiOIO}_{3}$ heterostructure deserve strong oxidizing property, which can oxide the absorbent $\mathrm{Hg}^{0}$ into $\mathrm{Hg}^{2+[11]}$.

\section{CONCLUSION}

In summary, the defect $\mathrm{TiO}_{2} / \mathrm{BiOIO}_{3}$ heterostructure was synthesized and may become a new research and application trend. The defect $\mathrm{TiO}_{2} / \mathrm{BiOIO}_{3}$ heterostructure exhibited excellent photocatalytic removal gas-phase mercury properties under visible light. The surface defect and interface heterostructure can greatly enhance the absorbance of the visible light, improve the transfer velocity of the photocarriers and reduce the recombination of the photo electron-hole pairs. However, these materials are not up to practical needs, from the entire field of photocatalysis technology research development. At present, there is an urgent need for photocatalytic physics starting from the quality, revealing the influence light with advanced experimental techniques the key factors in the catalytic reaction process. It is vital important that the understanding of the catalytic reaction mechanism, by macroscopic and qualitative description microscopic, quantitative research, on light absorption, electrons hole excitation, transport process and interface dynamics process.

\section{References}

1. E.G. Pacyna, J.M. Pacyna, N. Pirrone, Atmos. Environ. 35, 2987 (2001)

2. J. Li, Y. Yu, L. Zhang, Nanoscale 6, 8473 (2014)

3. R. X Zhou, J Wu, J Zhang, H Tian, P. K Liang, Appl. Catal. B: Envir. 204, 465 (2017)

4. R.L.V. Wal, V.M. Bryg, M.D. Hays, Anal. Chem. 83, 1924 (2011)

5. J. Cai, Y. Zhu, D. Liu, M. Meng, Z. Hu, Z. Jiang, Acs Catal. 5, 150 (2016)

6. A. Naldoni, M. Allieta, S. Santangelo, M. Marelli, F. Fabbri, S. Cappelli, C.L. Bianchi, R. Psaro, S.V. Dal, J. Am. Chem. Soc. 134, 7600 (2012)

7. R.X Zhou, J. Wu, J. Zhang, H. Tian, P.K Liang, T. Zeng, P. Lu, J.X Ren, T.F Huang, X. Zhou, Appl. Catal. B Envir. 45, 465 (2017)

8. Y. Sun, T. Xiong, F. Dong, H. Huang, W. Cen, Chem. Commun. 52, 8243 (2016)

9. X. Pan, Y.J. Xu, J. Phys. Chem. C 117, 17996 (2013)

10. Y. Huang, H. Li, M.S. Balogun, W. Liu, Y. Tong, X. Lu, H. Ji, Acs Appl. Mater. Inter. 6, 22920 (2014)

11. X.M Sun, J Wu, F.G Tian, W.B Zhang, Q.F Li, Mater. Res. Bull. 103, 247(2018). 